\title{
Confirmed quantitative trait loci for fatness and growth on pig chromosome 4
}

\author{
LENA MARKLUND, PER-ERIK NYSTRÖM, SUSANNE STERN, LENA ANDERSSON- \\ EKLUND \& LEIF ANDERSSON* \\ Department of Animal Breeding and Genetics, Swedish University of Agricultural Sciences, BMC, Box 597, S-751 24 \\ Uppsala, Sweden
}

\begin{abstract}
Quantitative trait loci (QTLs) with large effects on fatness and growth have been identified previously on pig chromosome 4 in an intercross between the European wild pig and Large White domestic pigs. Two $F_{2}$ sows, heterozygous for the actual chromosome region, were backcrossed to a Large White boar, and two backcross $\left(\mathrm{BC}_{1}\right)$ boars were in turn backcrossed to Large White/Landrace sows. One of the boars was heterozygous for an intact wild pig-derived QTL region, whereas the other carried a recombinant haplotype. A total of $85 \mathrm{BC}_{2}$ animals were produced. Phenotypical measurements included daily weight gain, ultrasonic measurements of fat depth at 70 and $90 \mathrm{~kg}$ and several carcass traits. QTL segregation was deduced using 15 markers previously assigned to chromosome 4. Highly significant QTL effects were observed on all fatness traits and on the length of the carcass. A small but significant effect on growth was also observed. The results confirm the presence of one or more QTLs on chromosome 4 affecting fatness and growth. There was a good agreement between the estimates of QTL effects in the $\mathrm{F}_{2}$ and $\mathrm{BC}_{2}$ generations. The results from the recombinant sire family allowed us to map the major QTL effect distal to the recombination breakpoint. We propose that this confirmed QTL with a major effect on fatness is designated FAT1.
\end{abstract}

Keywords: abdominal visceral fat, growth, pig, quantitative trait loci, subcutaneous fat.

\section{Introduction}

Genetic dissection of complex polygenic traits is a topical subject in humans, plants and animals (Lander \& Schork, 1994; Paterson, 1995; Georges \& Andersson, 1996). We have previously identified quantitative trait loci (QTLs) for growth and fatness traits in an intercross between two divergent populations of pigs, the European wild pig and the Large White domestic pig (Andersson et al., 1994; Knott et al., 1998). The study was the first genome-wide screening for QTLs in outbred animals. The QTLs with the largest effect were located on chromosome 4 and explained about $12 \%$ and $18 \%$ of the phenotypical variance in the $\mathrm{F}_{2}$ generation for growth and fatness traits respectively. The wild pig alleles at these loci were associated with reduced growth and higher fat deposition, as expected because of the intense selection for lean growth in modern domestic pigs.

*Correspondence. E-mail: leif.andersson@bmc.uu.se.
It is essential that the presence and location of QTLs are confirmed before attempts are made towards their cloning or exploitation in animal breeding by marker-assisted selection. There are, in fact, several reasons why one may fail to confirm the QTL in a subsequent experiment: e.g. (i) the original observation may be a type I error (see Lander \& Kruglyak, 1995); (ii) the QTL effect may depend on epistasis (Frankel \& Schork, 1996); (iii) a large QTL effect may be caused by several linked QTLs each with a small effect, and the linkage may break up in subsequent generations; (iv) the estimated QTL effect may be seriously inflated when the power of QTL detection is low (Georges et al., 1995); (v) segregation at the QTL in the recipient population may make some $\mathrm{BC}$ animals homozygous at the QTL or make the difference between QTL alleles too small to detect.

The objective of this study was to confirm the presence of QTLs with major effects on growth and fatness on pig chromosome 4 and to improve the 
map localization by backcrossing $F_{2}$ animals to domestic pigs.

\section{Materials and methods}

\section{Animals}

All $\mathrm{F}_{2}$ males from the intercross between European wild pig and Large White (Swedish Yorkshire) domestic pigs (Andersson et al., 1994) had been castrated in order to minimize the cost of producing the $F_{2}$ generation and could not be used for further breeding. Therefore, two $\mathrm{F}_{2}$ females were selected for breeding on the basis of marker information for the chromosome 4 region harbouring the fatness QTL. Marker data indicated that they were both heterozygous at the fatness QTL. One sow carried an intact wild pig-derived segment, whereas the other sow carried a recombinant wild pig/Large White haplotype (Fig. 1). The sows were backcrossed to a Large White boar. Two backcross $\left(\mathrm{BC}_{1}\right)$ males with QTL genotypes corresponding to the two mothers (Fig. 1) were identified and backcrossed to six Large White and four Large White/Landrace crossbred sows generating a total of $85 \mathrm{BC}_{2}$ progenies. After weaning, the progenies were placed in groups of eight per pen according to QTL genotype (as deduced using marker S0175), weight at 9 weeks of age and sex (gilts and boars separated). All 12 groups were fed a commercial diet (12.3 MJ, 16.8\% crude protein) ad libitum. Phenotypical measurements included daily weight gain, ultrasonic measurements of fat depth at 70 and $90 \mathrm{~kg}$ and several carcass traits (Lundström et al., 1995) as compiled in Table 1.

\section{Markers}

The segregation was studied using 15 chromosome 4 markers (Table 2), 14 of which were anonymous microsatellites and one random fragment length polymorphism (RFLP) (ATP1B1). The references for markers are given in Marklund et al. (1996) except for S0023 (Coppieters et al., 1993), S0214 (Robic et al., 1995), Sw445 and Sw856 (Rohrer et al., 1994).

\section{Linkage and QTL analysis}

The linkage analysis was performed using CRI-MAP version 2.4 (Green et al., 1990) with genotype information from all five generations. The order of markers obtained was in complete agreement with previously published maps for pig chromosome 4 (Archibald et al., 1995; Marklund et al., 1996; Rohrer et al., 1996). The CHROMPIC option in CRI-MAP was used to identify every recombination event among the animals and also to trace allelic origin (wild pig or domestic pig) through the pedigree.

The QTL analysis was carried out as singlemarker analysis using the sas package (procedure MIXED and procedure GLM; SAS, 1992). Preliminary statistical analyses revealed significant differences between sires and between sexes for the fatness traits; on average, females had higher fat deposition
Fig. 1 Summary of previous analysis using data from the $F_{2}$ generation of a wild pig intercross showing the presence of one or more fatness QTLs on pig chromosome 4; genetic markers used in the linkage analysis are shown below the $x$-axis. The wild pig segments (marked in black) carried by the selected $\mathrm{BC}_{1}$ sires of the present study are shown below. The dotted horizontal line represents the $5 \%$ genome-wide significance threshold.

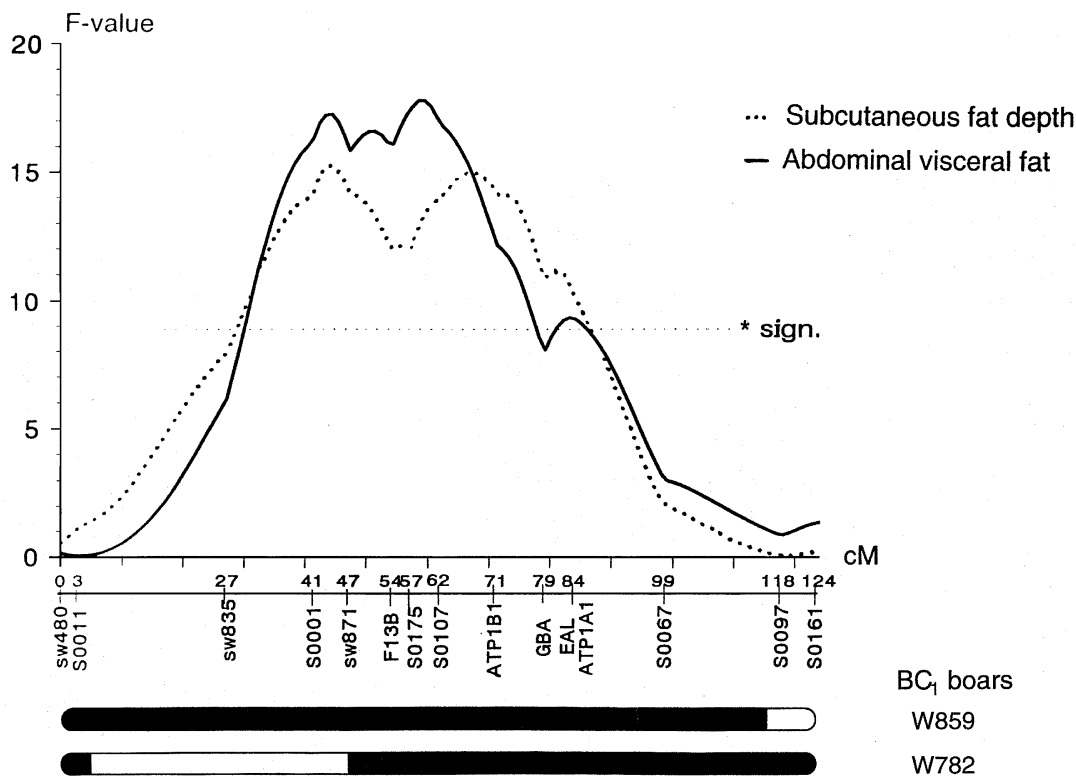

(C) The Genetical Society of Great Britain, Heredity, 82, 134-141. 
Table 1 Least-square means for different traits according to QTL genotype on pig chromosome 4

\begin{tabular}{|c|c|c|c|c|}
\hline Trait & $\begin{array}{l}\text { Heterozygote } \\
\text { wild/domestic }\end{array}$ & $\begin{array}{l}\text { Homozygote } \\
\text { domestic }\end{array}$ & $P$-value & $\begin{array}{c}\% \text { of } \\
\text { phenotypical } \\
\text { variance }\end{array}$ \\
\hline \multicolumn{5}{|l|}{ Fatness traits } \\
\hline Abdominal visceral fat $(\mathrm{kg})$ & $1.69 \pm 0.08$ & $1.30 \pm 0.07$ & $<0.0001$ & 15.4 \\
\hline Subcutaneous fat depth (mm) & $21.8 \pm 0.65$ & $19.5 \pm 0.62$ & $<0.0001$ & 7.3 \\
\hline \multicolumn{5}{|l|}{ Growth traits } \\
\hline Weight at slaughter (kg) & $107 \pm 0.98$ & $109 \pm 0.98$ & 0.038 & 5.0 \\
\hline Fat-free weight $(\%)$ & $57.8 \pm 0.73$ & $60.4 \pm 0.72$ & 0.0002 & 11.9 \\
\hline Daily weight gain $\left(\mathrm{g}\right.$ day $\left.^{-1}\right)$ & $610 \pm 9.8$ & $634 \pm 9.7$ & 0.015 & 5.8 \\
\hline Length of carcass $(\mathrm{cm})$ & $97.4 \pm 0.4$ & $98.9 \pm 0.4$ & 0.001 & 11.4 \\
\hline
\end{tabular}

than males. Therefore, the effects of sire and sex were adjusted for in the statistical analysis. A mixed model was used including sire, sex and marker as fixed effects and dam nested within sire and residual error as random effects. Interaction was tested at the marker position with the largest QTL effect on each trait. No significant interaction was found between marker and sire, marker and sex or sire and sex. Therefore, interactions were not included in further analysis.

Table 2 Pig chromosome 4 markers used in QTL analysis with frequencies of alleles originating from the wild (W) and domestic (D) founders in two $\mathrm{BC}_{1}$ sire families (W782 and W859)

\begin{tabular}{|c|c|c|c|c|c|}
\hline \multirow[b]{3}{*}{ Locus } & \multicolumn{4}{|c|}{ No. of progeny* } & \multirow[b]{3}{*}{ Map position (cM) } \\
\hline & \multicolumn{2}{|c|}{$\begin{array}{c}\text { Sire } \\
\text { W782 } \\
n=50\end{array}$} & \multicolumn{2}{|c|}{$\begin{array}{c}\text { Sire } \\
\text { W859 } \\
n=35\end{array}$} & \\
\hline & $\mathrm{W}$ & $\mathrm{D}$ & $\mathrm{W}$ & $\mathrm{D}$ & \\
\hline S0011 & - & - & 14 & 21 & 1.6 \\
\hline S0301 & - & - & 14 & 21 & 12.6 \\
\hline Sw835 & - & - & 16 & 19 & 16.6 \\
\hline S0001 & - & - & 17 & 18 & 27.6 \\
\hline Sw871 & - & - & 16 & 19 & 35.0 \\
\hline S0175 & 25 & 25 & 15 & 20 & 52.9 \\
\hline S0107 & 25 & 25 & - & - & 54.5 \\
\hline S0023 & 25 & 25 & 12 & 23 & 57.6 \\
\hline$A T P 1 B 1$ & 26 & 24 & 13 & 22 & 61.8 \\
\hline S0214 & 27 & 23 & 17 & 18 & 71.0 \\
\hline S0067 & - & - & 15 & 20 & 93.3 \\
\hline Sw445 & - & - & 15 & 20 & 98.4 \\
\hline S0097 & 32 & 18 & 16 & 19 & 119.2 \\
\hline S0161 & 32 & 18 & - & - & 124.3 \\
\hline Sw856 & 31 & 19 & - & - & 130.5 \\
\hline
\end{tabular}

* - Not informative because homozygous for Large White-derived segment (see Fig. 1) or homozygous for marker. 
The analysis of combined data involved only the markers, which were informative in both sires. In the separate analysis for each sire, the effect of sire was not included and dam (sire) was replaced by the effect of dam. Procedure MIXED was used to calculate all $F$-statistics. The proportion of the phenotypical variance explained by the QTL was estimated using procedure GLM as the differences in $r^{2}$-values between a model with and without the marker information. A nominal significance threshold was used, as the design of this experiment was to test for the presence of a QTL at a defined location in the genome.

\section{Results}

Development of backcross generations, $\mathrm{BC}_{1}$ and $\mathrm{BC}_{2}$

Two $\mathrm{BC}_{1}$ males were selected for this study on the basis of marker analysis. W859 carries a wild pig-derived segment, which covers almost the entire chromosome 4, whereas W782 carries a recombinant chromosome 4 (Fig. 1). By contrasting the observed QTL effects in the progeny groups of these sires, we should be able to evaluate whether the major QTL effect on fatness is located proximal or distal to the recombination breakpoint or if the recombination event will break up a QTL haplotype so that the QTL effect is markedly reduced in the W782 family. The wild pig chromosome segments carried by W782 and W859 originate from the same founder boar. This boar was homozygous for all markers in the interval S0107-S0067 $(38.8 \mathrm{cM})$, but flanking markers indicated that the wild pig segment of W782 and W859 originated from different chromosome 4 homologues.

The two $\mathrm{BC}_{1}$ males were backcrossed to Large White or Large White/Landrace females, and a total of $85 \mathrm{BC}_{2}$ progenies were used in the present study. Growth and fatness data were collected on all animals, and 15 chromosome 4 markers were used for segregation analysis (Table 2); the observed deviations from the expected 1:1 ratio for some markers were not statistically significant.

\section{QTL analysis}

The results for four major traits are depicted in Fig. 2 for each sire family and for combined data; it should be noted that these graphs do not represent the results of interval mapping but single point analyses for each marker, one at a time. Unequivocal evidence for QTL effects on fatness and growth traits was obtained. Although the QTL graphs differed considerably between sires, there was no significant heterogeneity in QTL effects between sires ( $P$ varies between 0.37 and 0.99 ).

Least-square means for different traits according to deduced QTL genotype are given in Table 1; the data were combined over sire families and represent estimates obtained with the most significant marker for each trait. The progenies that had received a wild pig chromosome segment were associated with markedly higher fat deposition $(P<0.0001)$, lower fat-free weight $(P<0.0002)$, reduced growth $(P=0.015)$ and shorter length of carcass $(P=0.001)$. There was no significant difference between QTL genotypes in body mass index (BMI), a frequently used parameter for obesity in humans; BMI was measured as (weight at slaughter)/(length of carcass $)^{2}$. The result suggests that the reduced fatness in animals homozygous for a domestic pig segment was accompanied by a higher muscularity. Finally, it was not possible to confirm a chromosome 4 effect on the length of the small intestine, as found in the $\mathrm{F}_{2}$ generation (Andersson et al., 1994; Knott et al., 1998).

\section{Discussion}

The results of this study confirm the presence of one or more QTLs on pig chromosome 4 affecting fatness and growth. To the best of our knowledge, this is the first time the segregation of QTLs over several generations has been documented in outbred populations of domestic animals. We propose that this confirmed pig QTL with a major effect on fatness is designated FAT1. The results imply that the chromosome 4 QTLs are not strongly dependent on epistasis, because the wild pig contribution to the $\mathrm{BC}_{2}$ population was only $12.5 \%$. There was a good agreement between the results in the $\mathrm{F}_{2}$ and $\mathrm{BC}_{2}$ populations, as regards both the location and the estimated effects of QTLs for growth and fatness. (Table 3 ). However, the data only allow a rough comparison of the QTL effects over generations, as there are some notable differences between the two data sets. First, the $F_{2}$ data represent the additive effect (i.e. half the difference between the two homozygous classes), whereas the $\mathrm{BC}_{2}$ data represent the difference between the heterozygote and one of the homozygotes. Moreover, the average growth rate differs markedly between the two populations, as the $\mathrm{F}_{2}$ generation and $\mathrm{BC}_{2}$ generations have $50 \%$ and $12.5 \%$ wild pig origin respectively. Consequently, the age and weight at slaughter differed significantly between the two generations. Finally, the $\mathrm{BC}_{2}$ animals were fed ad libitum, 

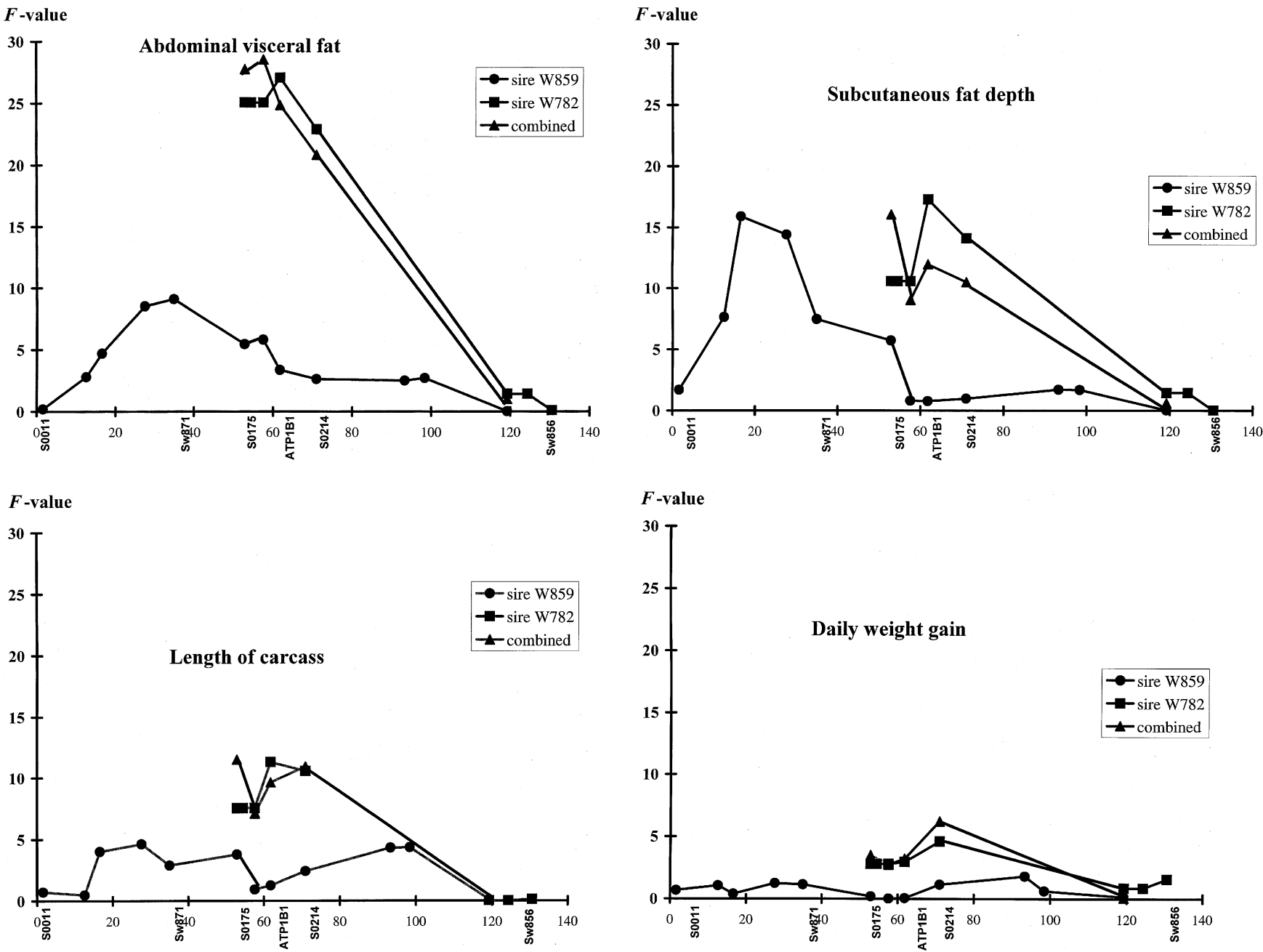

Fig. 2 Single-marker QTL analysis on pig chromosome 4 with $F$-values for (a) abdominal visceral fat, (b) subcutaneous fat depth, (c) length of carcass and (d) daily weight gain based on the $\mathrm{BC}_{2}$ generation. Results for individual sire families are shown together with combined data. The locations of the markers used in the QTL analysis are indicated by the symbols -, and $\mathbf{\Lambda}$. The map locations in $\mathrm{cM}$ of some chromosome 4 markers are indicated on the $x$-axis.

Table 3 Estimated QTL effects on pig chromosome 4 using $\mathrm{F}_{2}$ and $\mathrm{BC}_{2}$ animals from a wild pig-Large White intercross

\begin{tabular}{lcc}
\hline Trait & $\begin{array}{c}\mathrm{F}_{2} \text { animals* } \\
(n=191)\end{array}$ & $\begin{array}{c}\mathrm{BC}_{2} \text { animals } \\
(n=85)\end{array}$ \\
\hline Average subcutaneous fat $(\mathrm{mm})$ & $2.30 \pm 0.42$ & $2.33 \pm 0.58$ \\
Abdominal visceral fat $(\mathrm{kg})$ & $0.38 \pm 0.06$ & $0.39 \pm 0.07$ \\
Length of carcass $(\mathrm{mm})$ & $-8.0 \pm 0.23$ & $-14.9 \pm 4.4$ \\
Growth $\left(\mathrm{g} \mathrm{day}^{-1}\right)$ & $-23.5 \pm 4.9$ & $-24.3 \pm 9.7$ \\
\hline
\end{tabular}

*Additive effect estimated as half the difference between animals homozygous for wild pig allele and domestic pig allele respectively.

$\dagger$ Differences between animals heterozygous and homozygous for the domestic pig allele. 
whereas the $F_{2}$ animals were subjected to restricted feeding because of their low growth capacity. The only chromosome 4 QTL that we could not confirm was the one affecting the length of the small intestine. As pointed out above, there are many possible causes for a failure to confirm a QTL in a subsequent generation, and we do not have any indication which is the most plausible in this case.

The QTL analysis was carried out as a single marker analysis, as no software is yet available for interval mapping in backcross pedigrees. However, the result of a preliminary analysis using a stochastic method for interval mapping was in good agreement with the results presented here (Nyström et al., 1998).

The design of the experiment allowed us to conclude that a major QTL is located distal to the recombination breakpoint present in the wild pig-derived haplotype of sire W782 (compare Figs 1 and 2). This conclusion is based on the fact that the QTL effect was also significant in tests within the recombinant sire family only and that there was no significant interaction between sire families and QTL effects ( $P$ varies between 0.37 and 0.99 ). However, the fatness QTL graph for the 'non-recombinant' sire W859 (Fig. 2a and b) suggested the possible presence of a QTL located proximal to the recombination breakpoint as well. However, it must be emphasized that the precision in QTL location is poor with such small progeny groups as those used in this study. The shape of the QTL graph in the two sires may also differ because of genetic heterogeneity contributed by the founder boars or by the domestic sows. Thus, we conclude that there is clear evidence for a QTL located distal to the recombination breakpoint, and we cannot exclude the presence of additional QTL(s) proximal to the breakpoint. This illustrates the difficulties of QTL mapping in outbred populations.

The large effect of the fatness QTL and the fact that we have been able to follow Mendelian transmission of this QTL over four generations opens up possibilities for high-resolution QTL mapping using marker-assisted backcrossing. This implies that genetic markers are used to identify informative recombinants such as sire W782 in this study. The QTL genotype for each selected parent is then determined by progeny testing. In our case, about 25 progenies are needed to be $90 \%$ sure of detecting QTL segregation in a heterozygous parent, given the magnitude of the effects and residual variances estimated in this backcross. The map resolution obtained in such an undertaking should be a few centiMorgans if 5-10 different recombinants can be identified and tested. Such an experiment will reveal whether the large QTL effect on chromosome 4 is consistent with a single locus or several linked QTLs, each with a smaller effect.

Is it possible to clone a QTL such as the one affecting fatness on pig chromosome 4? This will depend on whether the QTL is a single gene effect or caused by mutations at several linked loci. In the latter case, it will be exceedingly difficult, if not impossible, with existing technology. Presently, the most reasonable strategy for approaching a QTL in a farm animal is by comparative positional candidate cloning. This strategy has recently been used successfully to reveal that pigs with the dominant white phenotype carry a duplication of the KIT gene (Johansson Moller et al., 1996) and that hypercholesterolaemia in one line of pigs is caused by a missense mutation in the LDLR gene (HaslerRapacz et al., 1998). We are convinced that markerassisted backcrossing will allow us to define the map location of the chromosome 4 QTL at a resolution (a few centiMorgans) capable of making a comparative screen for candidate genes meaningful.

Pig chromosome 4 shares homology with human chromosomes 1 and 8 (Rettenberger et al., 1995; Frönicke et al., 1996; Goureau et al., 1996). Unfortunately, the fatness QTL is located close to the border between these two regions of conserved synteny to human chromosomes. The pig comparative map of this region needs to be improved to facilitate the identification of potential candidate genes. A number of genes causing obesity in mice or rats have been identified (Bouchard, 1995). However, none of these is likely to be homologous to the fatness QTL on pig chromosome 4. The obese gene $(O B)$ encoding leptin is located on pig chromosome 18 (Neuenschwander et al., 1996), and the leptin receptor gene $(L E P R)$ maps to the distal region of pig chromosome 6q (Ernst et al., 1997). The other mouse obesity loci map to regions that are unlikely to share homology with the region of interest on pig chromosome 4.

The genetics of fat metabolism is of great agricultural significance, as manipulating the amount and distribution of fat in animal food products is a major objective in animal breeding. The genetic control of fat metabolism is also a central topic in human medicine, as obesity is a major health problem. In particular, abdominal visceral fat (AVF) obesity has a strong genetic component and is associated with severe diseases such as atherosclerosis, diabetes and hypertension (Bouchard, 1995; Pérusse et al., 1996). We have proposed previously (Andersson, 1996) that normal obesity (in contrast to morbid obesity) is 
not caused by a major biochemical defect but rather reflects an adaptive storage of energy when there is excess of food available; the pathological consequences may be secondary effects caused by a burden of fat tissue accumulated over many years. In this context, it should be noted that our data from the $\mathrm{F}_{2}$ and $\mathrm{BC}_{2}$ generations show that the wild pig in general has a higher fat deposition than purebred Large White domestic pigs and that the wild pig chromosome 4 QTL allele in particular was associated with higher fat deposition (Table 1). This ability to store fat is most certainly a selective advantage in the wild pig to survive periods of food shortage. The further characterization of the fatness QTL on pig chromosome 4 may therefore be an important animal model for the genetics of normal obesity in humans. The line of pigs carrying this wild pig QTL allele may also be useful when evaluating new drugs for the treatment of obesity.

\section{Acknow ledgements}

This study was supported financially by the Swedish Research Council for Forestry and Agriculture. We wish to thank Ulla Schmidt, Eva Norling and Ingemar Hansson for help in collecting phenotypical data, and Max Rothschild, U.S. Pig Genome Coordinator, for providing microsatellite primers as part of the co-operative gene mapping efforts supported by the U.S. National Genome program NRSP-8.

\section{References}

Andersson, L. 1996. Genes and obesity. Ann. Med., 28, $5-7$.

ANDERSSON, L., HALEY, C. S., ELLEGREN, H., KNOTT, S., JOHANSSON, M., ANDERSSON, K. ET AL. 1994. Genetic mapping of quantitative trait loci for growth and fatness in pigs. Science, 263, 1771-1774.

ARCHIBALD, A. L., HALEY, C. S., BROWN, J. F., COUPERWHITE, S., MCQueEn, H. A., NiChOlson, D. ET AL. 1995. The PIGMaP consortium linkage map of the pig (Sus scrofa). Mamm. Genome, 6, 157-175.

BOUCHARD, C. 1995. The genetics of obesity: from genetic epidemiology to molecular markers. Mol. Med. Today, $\mathbf{1}$, 45-50.

COPPIETERS, W., VAN DE WEGHE, A., PEELMAN, L., DEPICKER, A., VAN ZEVEREN, A. AND BOUQUET, Y. 1993. Characterization of porcine polymorphic microsatellite loci. Anim. Genet., 24, 163-170.

ERNST, C. W., KAPKE, P. A., YERLE, M. AND ROTSCHILD, M. 1997. The leptin receptor gene (LEPR) maps to porcine chromosome 6. Mamm. Genome, 8, 226.

FRANKEL, W. N. AND SCHORK, N. J. 1996. Who's afraid of epistasis? Nature Genet., 14, 371-373.

FRÖNICKE, L., CHOWDHARY, B. P., SCHERTHAN, H. AND
Gustavsson, I. 1996. A comparative map of the porcine and human genomes demonstrates ZOO-FISH and gene mapping-based chromosomal homologies. Mamm. Genome, 7, 285-290.

GEORGES, M. AND ANDERSSON, L. 1996. Livestock genomics comes of age. Genome Res., 6, 907-921.

GEORGES, M., NIELSEN, D., MACKINNON, M., MISHRA, A., OKIMOTO, R., PASQUiNO, A. T. ET AL. 1995. Mapping quantitative trait loci controlling milk production in dairy cattle by exploiting progeny testing. Genetics, $\mathbf{1 3 9}$, 907-920.

GOUREAU, A., Yerle, M., SCHMitz, A., RIQUET, J., MILAN, D., PINTON, P. ET AL. 1996. Human and porcine correspondence of chromosome segments using bidirectional chromosome painting. Genomics, 36, 252-262.

GREEN, P., FALlS, K. AND CROOK, S. 1990. Documentation for CRI-MAP, Version 2.4. Washington University School of Medicine, St Louis, MO.

HASLER-RAPACZ，J.， ELLEGREN， H., FRIDOLFSSON, A. K., KIRKPATRICK, B., KIRK, S., ANDERSSON, L. AND RAPACZ, J. 1998. Identification of a mutation in the low density lipoprotein receptor gene associated with recessive familial hypercholesterolemia in swine. Am. J. Med. Genet., 76, 379-386.

JOHANSSON MOLLER, M., CHAUDHARY, R., HELLMÉN, E., HÖYHEIM, B., CHOWDHARY, B. P. AND ANDERSSON, L. 1996. Pigs with dominant white coat color phenotype carry a duplication of the KIT gene encoding the mast/ stem cell growth factor receptor. Mamm. Genome, 7, $822-830$.

KNOTT, S. A., MARKLUND, L., HALEY, C. S., ANDERSSON, K., DAVIES, W., ELLEGREN, H. ET AL. 1998. Multiple marker mapping of quantitative trait loci in a cross between outbred wild boar and Large White pigs. Genetics, 149, 1069-1080.

LANDER, E. S. AND KRUGLYAK, L. 1995. Genetic dissection of complex traits: guidelines for interpreting and reporting linkage results. Nature Genet., 11, 241-247.

LANDER, E. S. AND SCHORK, N. J. 1994. Genetic dissection of complex traits. Science, 265, 2037-2047.

LUNDSTRÖM, K., KARLSSON, A., HÅKANSSON, J., HANSSON, I., JOHANSSON, M., ANDERSSON, L. AND ANDERSSON, K. 1995. Production, carcass and meat quality traits of $\mathrm{F}_{2}$-crosses between European Wild Pigs and domestic pigs including halothane gene carriers. Anim. Sci., 61, 325-331.

MARKLUND, L., JOHANSSON MOLLER, M., HØYHEIM, B., DAVIES, W., FREDHOLM, M., JUNEJA, R. K. ET $A L$. 1996. A comprehensive linkage map of the pig based on a wild pig-Large White intercross. Anim. Genet., 27, 255-269.

NEUENSCHWANDER, S., RETTENBERGER, G., MEIJERINK, E., JÖRG, H. AND STRANZINGER, G. 1996. Partial characterization of porcine obesity gene (OBS) and its localization to chromosome 18 by somatic cell hybrids. Anim. Genet., 27, 275-278.

NYSTRÖM, P.-E., ANDERSSON-EKLUND, L., STERN, S., MARKLUND, L., ANDERSSON, L. AND HALEY, C. 1998. Use of a stochastic method for interval mapping of quantitative trait loci on porcine chromosome 4. In: Proc. 6th 
World Congr. Genet. Appl. Livestock Prod., Armidale, 26, 465-468.

PATERSON, A. H. 1995. Molecular dissection of quantitative traits: progress and prospects. Genome Res., 5, 321-333.

PÉRUSSE, L., DESPRES, J.-P., LEMIEUX, S., RICE, T., RAO, D. C. AND BOUCHARD, C. 1996. Familial aggregation of abdominal visceral fat level: results from the Quebec family study. Metab. Clin. Exp., 45, 378-382.

RETTENBERGER, G., KLETT, C., ZECHNER, U., KUNZ, J., VOGEL, W. AND HAMEISTER, H. 1995. Visualization of the conservation of synteny between humans and pigs by heterologous chromosomal painting. Genetics, 26, 372-378.
Robic, A., PARrou, J. L., Yerle, M., GOURREAU, A., DALENS, M., MILAN, D. AND GELlin, J. 1995. Pig microsatellites isolated from cosmids revealing polymorphism and localized on chromosomes. Anim. Genet., 26, 1-6.

ROHRER, G. A., ALEXANDER, L. J., HU, Z., SMITH, T. P., KEele, J. W. AND BEATTIE, C. W. 1996. A comprehensive map of the porcine genome. Genome Res., 6, 371-391.

ROHRER, G. A., ALEXANDER, L. J., KEELE, J. W., SMITH, T. P. AND BEATtiE, C. W. 1994. A microsatellite linkage map of the porcine genome. Genetics, 136, 231-245.

SAS. 1992. SAS@Technical Report P-229, SAS/STAT® Software: Changes and Enhancements, Release 6.07. SAS Institute Inc, Cary, NC. 